\title{
Mitral valve repair versus replacement for patients with preserved left ventricular function without heart failure symptoms
}

\author{
Edward L. Hannan, PhD, ${ }^{a}$ Zaza Samadashvili, MD, ${ }^{a}$ Craig R. Smith, MD, ${ }^{\mathrm{b}}$ Stephen J. Lahey, MD, \\ Jeffrey P. Gold, MD, ${ }^{\mathrm{d}}$ Desmond Jordan, MD, ${ }^{\mathrm{b}}$ Thoralf M. Sundt III, MD, ${ }^{\mathrm{e}}$ Leonard Girardi, MD, ${ }^{\mathrm{f}}$ \\ Mohammed H. Ashraf, MD, ${ }^{g}$ and Joanna Chikwe, MD $^{\text {h }}$
}

\section{ABSTRACT}

Objective: The purposes of this study are to compare outcomes of mitral valve repair (MV-repair) and mitral valve replacement for patients with severe mitral regurgitation with preserved ventricular function and no congestive heart failure (CHF) symptoms and to examine variations in surgeon choice of procedure and outcomes by surgeon volume.

Methods: In total, 2259 consecutive patients in 42 New York State hospitals with the characteristics mentioned previously who underwent mitral valve repair (1801, 79.7\%) or replacement between January 1, 2008, and December 31, 2014, were identified from a mandatory statewide clinical registry. Propensitymatching was used to compare mortality and competing risk analyses were used to compare nonfatal outcomes. Median follow-up was 4.0 years. The use of mitral repair and risk-adjusted mortality for surgery were also examined as a function of individual surgeon mitral case volume.

Results: Propensity-matched patients who underwent MV-repair experienced a significantly lower mortality rate at 4 years $(3.5 \%$ vs $12.1 \%, P<.001)$. Greater-volume surgeons were more likely to perform MV-repairs (92\% vs $84 \%, 74 \%$, and $69 \%$ in lower volume quartiles, respectively). No significant differences in mortality were observed among volume quartiles.

Conclusions: Patients with chronic severe primary mitral valve regurgitation with preserved ventricular function and no CHF symptoms who underwent MV-repair experienced lower mortality and no different reoperation, CHF, or stroke readmission rates than patients who underwent replacement. Greater-volume surgeons were more likely than their lower volume counterparts to choose mitral repair. Repair should be considered as the surgical option for these patients whenever possible. (J Thorac Cardiovasc Surg 2019;157:1432-9)

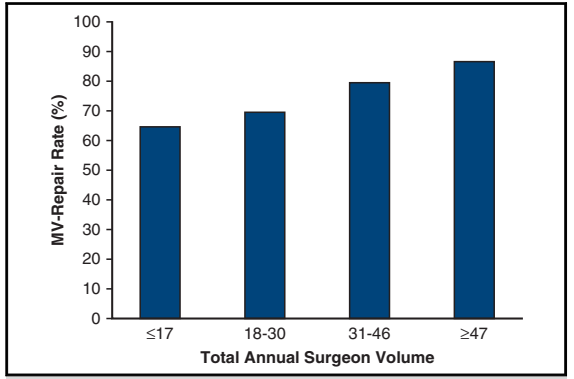

Percentage of all mitral valve procedures that are repairs by surgeon volume quartile.

\section{Central Message}

Greater-volume surgeons were more likely to choose mitral repair for patients with chronic severe primary mitral valve regurgitation with preserved ventricular function and no $\mathrm{CHF}$ symptoms.

\section{Perspective}

This is the first large, multicenter study to show that patients with chronic severe primary mitral valve regurgitation with preserved ventricular function and no CHF symptoms experienced better outcomes with MV-repair and that greater-volume surgeons were more likely to choose mitral repair. Repair should be considered as the procedural option for these patients whenever possible.

See Commentaries on pages 1440 and 1442.

\footnotetext{
From the a School of Public Health, University at Albany, State University of New York, Albany, NY; ' Department of Surgery, Columbia-Presbyterian Medical Center, New York, NY; ${ }^{\mathrm{c} D i v i s i o n}$ of Cardiothoracic Surgery, University of Connecticut, Storrs, Conn; ${ }^{\mathrm{d}}$ University of Nebraska Medical Center, Omaha, Neb; ${ }^{\mathrm{e}}$ Cardiac Surgical Division, Massachusetts General Hospital, Boston, Mass; ${ }^{\mathrm{f}}$ Department of Cardiothoracic Surgery, Weill Cornell Medical Center, New York, NY; ' Department of Cardiothoracic Surgery, Kaleida Health, Buffalo, NY; and ${ }^{\mathrm{h}}$ Department of Cardiothoracic Surgery, Stony Brook School of Medicine, Stony Brook, NY and Department of Cardiothoracic Surgery, Mount Sinai Hospital, New York, NY.
}

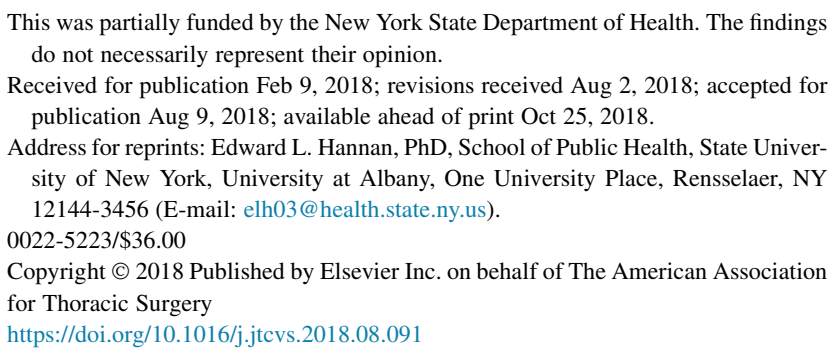

This was partially funded by the New York State Department of Health. The findings do not necessarily represent their opinion. publication Aug 9, 2018; available ahead of print Oct 25, 2018.

Adress for reprints: Edward L. Hannan, PhD, School of Public Health, State Univer 12144-3456 (E-mail: elh03@health.state.ny.us). $0022-5223 / \$ 36.00$ for Thoracic Surgery https://doi.org/10.1016/j.jtcvs.2018.08.091 


\section{Abbreviations and Acronyms \\ ACC $/ \mathrm{AHA}=$ American Heart Association/ \\ American College of Cardiology \\ AHR = adjusted hazard ratio \\ $\mathrm{CABG}=$ coronary artery bypass graft \\ $\mathrm{CHF}=$ congestive heart failure \\ CIF = cumulative incidence function \\ CSRS = Cardiac Surgery Reporting System \\ LVF = left ventricular function \\ MR = mitral regurgitation \\ MVR = mitral valve replacement \\ MV-repair $=$ mitral valve repair \\ SPARCS $=$ Statewide Planning and research Cooperative System}

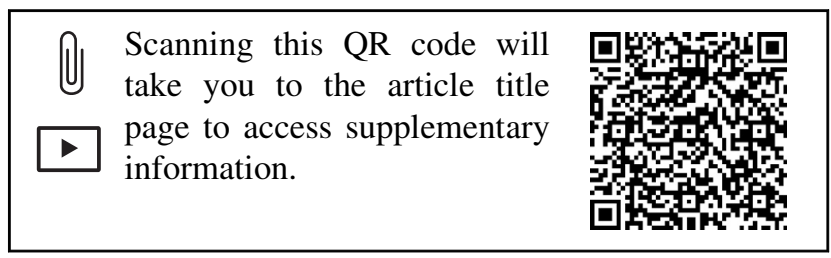

Numerous studies have compared treatment with mitral valve repair (MV-repair) and mitral valve replacement (MVR) for patients with severe mitral regurgitation (MR) ${ }^{1-14}$ including some studies that have limited patient populations such as elderly patients ${ }^{4-8}$ or to a specific disease etiology. ${ }^{9-14}$ However, no multicenter studies in contemporary practice have investigated relative outcomes for these 2 procedures, or choice of procedure, among patients with chronic severe primary MR with preserved left ventricular function (LVF) and no symptoms of congestive heart failure (CHF). This is important because MV-repair was identified as "reasonable" compared with watchful waiting in asymptomatic patients with chronic severe primary MR with preserved LVF in whom the likelihood of a successful and durable repair without residual MR is greater than $95 \%$ with an expected mortality rate of less than $1 \%$ when performed at a Heart Valve Center of Excellence in the recent American Heart Association/American College of Cardiology (ACC/ AHA) guidelines (Video 1). ${ }^{15}$ Furthermore, there is little or no information about practice pattern variations in surgeons' procedural choices for this population of patients.

There are 3 primary purposes of the study: (1) to compare outcomes (mortality, readmission rates, and reoperation rates) of MV-repair and MVR for chronic severe primary MR with preserved LVF without CHF symptoms for various time intervals up to 4 years; (2) to examine the relationship of surgeon volume with the choice of procedure to

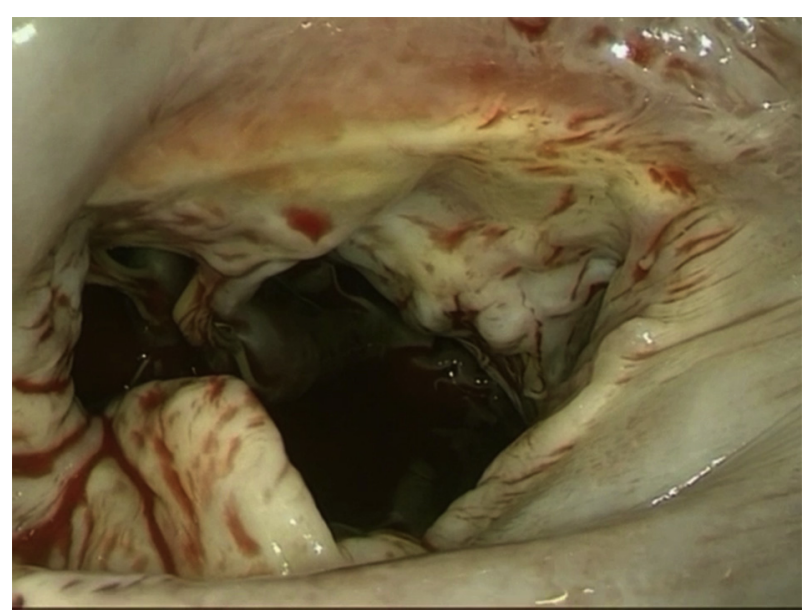

VIDEO 1. Mitral valve repair for preserved left ventricular function without heart failure. Video available at: https://www.jtcvs.org/article/ S0022-5223(18)32485-1/fulltext.

use; and (3) to examine the relationship between surgeon volume and risk-adjusted mortality for MV procedures.

\section{METHODS \\ Databases}

The databases used to conduct the study were New York's Cardiac Surgery Reporting System (CSRS), New York's Vital Statistics file, and New York's Statewide Planning and Research Cooperative System (SPARCS). CSRS is a mandatory statewide clinical registry that was created in 1989 to evaluate and improve the quality of coronary artery bypass graft (CABG) surgery and cardiac valve procedures in New York through the risk-adjustment of outcomes and dissemination of reports to hospitals, surgeons, and the public. It contains demographics; patient risk factors; complications; hospital and surgeon identifiers; admission, discharge and procedure dates; and discharge disposition for all CABG and valve surgery performed in nonfederal hospitals in the state. Current CHF is one of the comorbidities contained in the registry, and LVF is also captured through reporting of left ventricular ejection fraction. Vital statistics data were matched to CSRS using unique patient identifiers to obtain deaths that occurred after discharge following the index procedure. SPARCS data were used to exclude patients with rheumatic disease and cardiomyopathy and to identify subsequent readmissions for stroke and CHF by matching CSRS and SPARCS data. SPARCS data and hospital medical record reviews were also used to audit data for completeness and accuracy.

\section{Patients and Hospitals}

Patients chosen for the study were patients with chronic severe primary MR without current CHF (defined as paroxysmal nocturnal dyspnea, dyspnea on exertion due to heart failure, or chest radiograph showing pulmonary congestion) and with preserved LVF (defined as LVF $\geq 55 \%$ because hospitals were told to code normal LVF as $55 \%$ ). This group was chosen because it is as close as possible to the group for whom MV-repair was identified as "reasonable" in the recent ACC/AHA guidelines. ${ }^{15}$ First, all 8481 patients with chronic severe MR with undergoing MVR or MVrepair between January 1, 2008 and December 31, 2014 in New York State nonfederal hospitals were identified. A total of 5356 (63.2\%) underwent MV-repair. Patients were then sequentially excluded if they were out-ofstate residents (887), had invalid Social Security numbers (318), previous valve surgery (745), endocarditis (472), mitral valve stenosis (557), coronary artery disease (621), previous revascularization (1239), malignant ventricular arrhythmia (44), shock (18), unstable hemodynamics (96), 
TABLE 1. Baseline characteristics for asymptomatic patients with chronic severe primary MR and LVEF $\geq 55 \%$ by mitral valve surgery type: New York State, 2008 to 2014

\begin{tabular}{|c|c|c|c|c|}
\hline Risk factor & $\begin{array}{c}\text { All cases, } n(\%) ; \\
\text { total patients }=\mathbf{2 2 5 9}\end{array}$ & $\begin{array}{c}\text { Mitral valve } \\
\text { replacement, } \mathbf{n}(\%) ; \\
\text { total patients }=\mathbf{4 5 8}\end{array}$ & $\begin{array}{c}\text { MV-repair, n (\%); } \\
\text { total patients = } 1801\end{array}$ & ASD \\
\hline Surgeon MV-repair volume & $24.4( \pm 20.2)$ & $13.9( \pm 12.5)$ & $27.0( \pm 20.9)$ & 76.5 \\
\hline Age, y & $60.9( \pm 13.1)$ & $64.5( \pm 14.3)$ & $60.0( \pm 12.6)$ & 33.2 \\
\hline Body surface area, $\mathrm{m}^{2}$ & $1.9( \pm 0.3)$ & $1.9( \pm 0.3)$ & $1.9( \pm 0.3)$ & 21.3 \\
\hline Stenosis, aortic, or/and tricuspid valves & $43(1.9)$ & $19(4.1)$ & $24(1.3)$ & 17.3 \\
\hline Aortic valve incompetence, mild & $293(13.0)$ & $71(15.5)$ & $222(12.3)$ & 9.2 \\
\hline Aortic valve incompetence, moderate/severe & $62(2.7)$ & $13(2.8)$ & $49(2.7)$ & 0.7 \\
\hline Tricuspid valve incompetence, mild & $655(29.0)$ & $131(28.6)$ & $524(29.1)$ & 1.1 \\
\hline Tricuspid valve incompetence, moderate/severe & $279(12.4)$ & $77(16.8)$ & $202(11.2)$ & 16.2 \\
\hline Female sex & $1052(46.6)$ & $289(63.1)$ & $763(42.4)$ & 42.5 \\
\hline \multicolumn{5}{|l|}{ Race } \\
\hline White & $1984(87.8)$ & $373(81.4)$ & $1611(89.5)$ & 22.9 \\
\hline Black & $166(7.3)$ & $56(12.2)$ & $110(6.1)$ & 21.3 \\
\hline Other & $109(4.8)$ & $29(6.3)$ & $80(4.4)$ & 8.4 \\
\hline Peripheral vascular disease & $43(1.9)$ & $15(3.3)$ & $28(1.6)$ & 11.2 \\
\hline Cerebrovascular disease & $108(4.8)$ & $40(8.7)$ & $68(3.8)$ & 20.6 \\
\hline CHF, past & $267(11.8)$ & $105(22.9)$ & $162(9.0)$ & 38.7 \\
\hline COPD & $276(12.2)$ & $101(22.1)$ & $175(9.7)$ & 34.2 \\
\hline Extensive aortic atherosclerosis & $15(0.7)$ & $7(1.5)$ & $8(0.4)$ & 11 \\
\hline Diabetes & $118(5.2)$ & $46(10.0)$ & $72(4.0)$ & 23.8 \\
\hline \multicolumn{5}{|l|}{ Renal dysfunction } \\
\hline Serum creatinine $1.3-2.0$ & $163(7.2)$ & $39(8.5)$ & $124(6.9)$ & 6.1 \\
\hline Serum creatinine $\geq 2.1$ or/and renal dialysis & $36(1.6)$ & $20(4.4)$ & $16(0.9)$ & 21.9 \\
\hline
\end{tabular}

$M V$-repair, Mitral valve repair; $A S D$, absolute standardized difference; $C H F$, congestive heart failure; $C O P D$, chronic obstructive pulmonary disease.

current CHF (2869), low ejection fraction (3,150), rheumatic disease (45), and cardiomyopathy (85). Out-of-state residents were excluded because their deaths could not be ascertained using New York vital statistics data. The final study sample consisted of 2259 patients, 458 (20.3\%) of whom underwent MVR and 1801 (79.7\%) of whom underwent MV-repair. The median follow-up period was 4.0 years for both patients MV-repair and patients undergoing MVR. Patients with CHF were excluded to obtain asymptomatic patients, although we realize that patients may have symptoms that do not meet the definition for CHF (physician diagnosis of $\mathrm{CHF}$ and symptoms requiring treatment for $\mathrm{CHF}$ ).

\section{Outcomes}

Mortality, postoperative stroke, $\mathrm{CHF}$, and reoperation (repeat surgery on the mitral valve) were compared for the 2 procedures for the 4 -year period after the procedure. For the nonmortality outcomes, only the first occurrence is considered.

\section{Statistical Analysis}

Mortality. For examining mortality differences, propensity score matching was used to identify a set of MV-repair/MVR pairs matched on all available patient-level risk factors so that the selection bias associated with our observational study could be minimized. Surgeon repair volume was also used as a matching variable to determine its impact on the difference in MV-repair and MVR outcomes. Before propensity matching, the prevalences of all available patient risk factors were compared for MV-repair and MVR patients, and standardized differences of observed prevalences were calculated for all the variables. Compared with patients undergoing MVR, patients undergoing MV-repair had less aortic or tricuspid stenosis or tricuspid incompetence, were younger, less likely to be female, more likely to be white, and had a lower prevalence of comorbidity (Table 1).

Next, the propensity score was obtained by developing a logistic regression model that predicted the probability that a given patient would receive MV-repair versus replacement. The statistical model used to develop propensity scores for the propensity matching process is presented in Table E1. The propensity score was used to match patients on a 1-to-1 basis so as to minimize the overall distance in propensity scores between the groups. ${ }^{16-19}$ Patient characteristics for MVR and MV-repair patients were matched as long as their estimated log-odds from the logistic regression model were no more than 0.2 standard deviations apart. Standardized differences in the prevalence of propensity model variables were then recalculated. The propensity matching process resulted in a total of 450 matched pairs of patients. Table 2 and Figures $\mathrm{E} 1$ and $\mathrm{E} 2$ demonstrate that the risk factors were quite dissimilar before matching (Figure E1), but that propensity-matched pairs are quite similar with respect to risk factor prevalences (Figure E2), with no patient characteristics having a standardized difference larger than $10 \%$ (the largest difference was $7.5 \%$ ).

The propensity-matched pairs were then used to analyze differences in mortality rates between the 2 groups. To eliminate further differences within the matched pairs, a Cox proportional hazards model was used to 
TABLE 2. Baseline characteristics of mitral valve replacement and MV-repair patients after propensity matching: New York State, 2008 to 2014

\begin{tabular}{|c|c|c|c|c|}
\hline Risk factor & $\begin{array}{c}\text { All cases, n (\%); } \\
\text { total patients }=900\end{array}$ & $\begin{array}{c}\text { Mitral valve } \\
\text { replacement, } n(\%) ; \\
\text { total patients }=450\end{array}$ & $\begin{array}{l}\text { MV-repair, n (\%) } \\
\text { total patients; } 450\end{array}$ & ASD \\
\hline Surgeon MV-repair volume & $14.3( \pm 12.1)$ & $14.1( \pm 12.5)$ & $14.6( \pm 11.8)$ & 4.3 \\
\hline Age, y & $64.1( \pm 13.3)$ & $64.3( \pm 14.2)$ & $64.0( \pm 12.4)$ & 2.6 \\
\hline Body surface area, $\mathrm{m}^{2}$ & $1.9( \pm 0.3)$ & $1.9( \pm 0.3)$ & $1.9( \pm 0.3)$ & 0.4 \\
\hline Stenosis, aortic or/and tricuspid valves & $29(3.2)$ & $16(3.6)$ & $13(2.9)$ & 3.8 \\
\hline Aortic valve incompetence, mild & $142(15.8)$ & $70(15.6)$ & $72(16.0)$ & 1.2 \\
\hline Aortic valve incompetence, moderate/severe & $26(2.9)$ & $13(2.9)$ & $13(2.9)$ & 0 \\
\hline Tricuspid valve incompetence, mild & $245(27.2)$ & $129(28.7)$ & $116(25.8)$ & 6.5 \\
\hline Tricuspid valve incompetence, moderate/severe & $152(16.9)$ & $74(16.4)$ & $78(17.3)$ & 2.4 \\
\hline Female sex & $584(64.9)$ & $284(63.1)$ & $300(66.7)$ & 7.5 \\
\hline \multicolumn{5}{|l|}{ Race } \\
\hline White & $743(82.6)$ & $369(82.0)$ & $374(83.1)$ & 2.9 \\
\hline Black & $102(11.3)$ & $53(11.8)$ & 49 (10.9) & 2.8 \\
\hline Other & $55(6.1)$ & $28(6.2)$ & $27(6.0)$ & 0.9 \\
\hline Peripheral vascular disease & $29(3.2)$ & $14(3.1)$ & $15(3.3)$ & 1.3 \\
\hline Cerebrovascular disease & $67(7.4)$ & $37(8.2)$ & $30(6.7)$ & 5.9 \\
\hline CHF, past & $192(21.3)$ & $99(22.0)$ & 93 (20.7) & 3.3 \\
\hline COPD & $186(20.7)$ & $99(22.0)$ & $87(19.3)$ & 6.6 \\
\hline Extensive aortic atherosclerosis & $11(1.2)$ & $6(1.3)$ & $5(1.1)$ & 2 \\
\hline Diabetes & $78(8.7)$ & $42(9.3)$ & $36(8.0)$ & 4.7 \\
\hline \multicolumn{5}{|l|}{ Renal dysfunction } \\
\hline Serum creatinine $1.3-2.0$ & $73(8.1)$ & $39(8.7)$ & 34 (7.6) & 4.1 \\
\hline Serum creatinine $\geq 2.1$ or/and renal dialysis & $24(2.7)$ & $13(2.9)$ & $11(2.4)$ & 2.8 \\
\hline
\end{tabular}

$M V$-repair, Mitral valve repair; $A S D$, absolute standardized difference; $C H F$, congestive heart failure; $C O P D$, chronic obstructive pulmonary disease.

calculate the hazard ratio for the 2 procedures among matched pairs of patients. The impact of repair volume on mortality and the interaction between type of procedure and volume were also investigated.

Morbidity. To examine differences in nonfatal outcomes (CHF readmissions, stroke readmissions, mitral valve reoperations), we used a competing risk framework and calculated subdistribution hazard models and cumulative incidence functions (CIFs) to examine hazard ratios and compare the relative incidence of each nonfatal outcome for MV-repair and MVR while taking the competing risk of death into account. ${ }^{20,21}$ Gray's test was used to test for the significance of differences in CIFs. ${ }^{22}$ These analyses were conducted using the propensity-matched pairs of patients.

Surgeon volume. The surgeon volume associated with each patient was calculated as the number of MV procedures performed in the 365 days before the date of the patient's procedure by the patient's surgeon, and then surgeon volume was separated into quartiles $(\leq 17,18-30,31-46$, and $\geq 47$ ). The percentages of repairs were then compared across volume quartiles. A Cox proportional hazards model with a robust covariance matrix that accounts for correlation of survival times for patients within hospital and surgeon clusters ${ }^{23,24}$ was used to compare 4-year risk-adjusted mortality for all MV surgery for the $4 \mathrm{MV}$ volume categories after controlling for all patient-level risk factors. First, we confirmed that the proportional hazards assumption was justified. ${ }^{25}$ Risk-adjusted rates were computed using the method described by Ghali and colleagues. ${ }^{26}$ All tests were 2 -sided and conducted at the .05 level, and all analyses were conducted in SAS 9.2 (SAS Institute, Cary, NC).

\section{RESULTS \\ Mortality}

The respective in-hospital/30-day mortality rates for propensity matched MV-repair and MVR patients were $0.7 \%$ and $2.0 \%(P=.08)$. Subsequent mortality rates were $1.6 \%$ versus $4.7 \%(P=.002)$ at 1 year and $3.5 \%$ versus $12,1 \%(P<.001)$ at 4 years. The mortality rate for the entire 4-year period was significantly greater for patients undergoing MVR than for patients undergoing MV-repair (adjusted hazard ratio [AHR], 2.86; 95\% confidence interval, 1.097.45), see Figure 1 and Table 3. The interaction term for surgeon repair volume and MVR was not significant $($ AHR $=1.05, P=.15)$.

\section{Morbidity}

Figure 2, $A$ and $C$, and Table 3 present the CIFs and AHRs for the 3 nonfatal outcomes (CHF, stroke, reoperation) for propensity-matched patients. There were no significant differences in the incidence of any of the nonfatal outcomes. either before or after adjustment. Surgeon volume was significant for stroke (AHR, $1.03 ; P=.002$ ), 


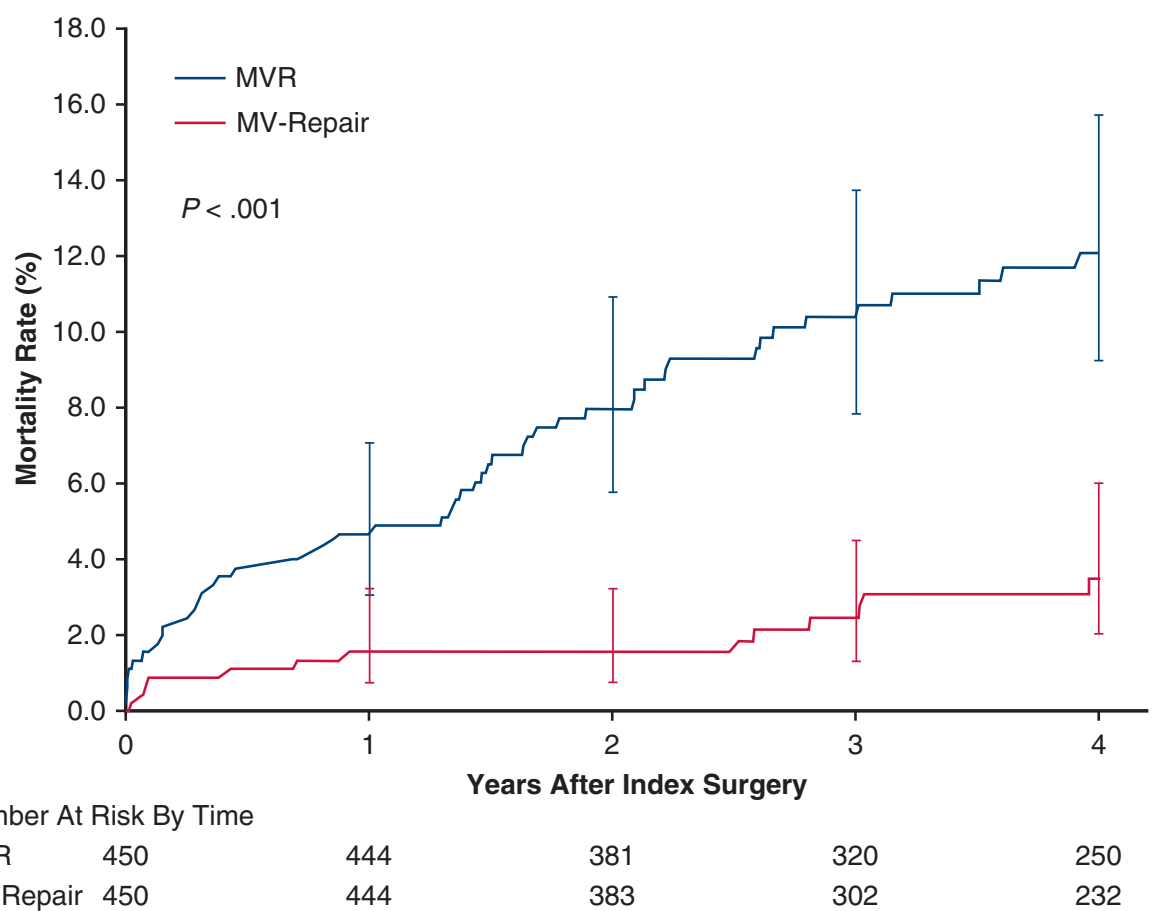

FIGURE 1. Mortality for MV-repair and MVR for propensity-matched patients. MV-repair, Mitral valve repair; $M V R$, mitral valve replacement.

denoting greater stroke rates for greater MV-repair volume surgeons. None of the interactions between surgeon repair volume and MVR were significant.

\section{Surgeon Volume}

Figure 3 demonstrates the variation across surgeons in the use of MV-repair versus MVR for patients with MR. When surgeon volumes were separated into quartiles $(\leq 17$ procedures, 18-30, 31-46, >47), the respective numbers of surgeons from lowest to highest quartiles were $121,64,37$, and 21 . As indicated in the figure, the percent mitral valve procedures that were repairs rose monotonically from $69 \%$ in the lowest volume quartile to $74 \%$ to $84 \%$ to $92 \%$ in the highest volume quartile $(P<.001$ for trend).
The respective 4-year risk-adjusted mortality rates for surgeon volume quartiles were $5.5 \%, 5.1 \%, 5.9 \%$, and $4.1 \%$. There was no significant difference in mortality rates among quartiles (AHR for highest volume quartile vs other quartiles $=0.63 ; 95 \%$ confidence interval, 0.36-1.09).

\section{DISCUSSION}

Although many studies have compared outcomes of MV-repair and MVR for patients with severe MR, much is still unknown about how patients are treated in contemporary practice. Previous studies did not examine outcome differences for patients with chronic severe primary MR with preserved LVF and no CHF symptoms. We chose this specific group of patients because according to the

TABLE 3. Mortality, stroke, CHF readmission, and mitral valve reoperation 4-year outcomes for propensity-matched patients

\begin{tabular}{|c|c|c|c|c|c|c|c|}
\hline \multirow[b]{2}{*}{ Outcomes } & \multicolumn{3}{|c|}{ Adjusted hazards (MVR vs MV-repair) } & \multicolumn{4}{|c|}{ Surgeon MV-repair annual volume variables } \\
\hline & $\begin{array}{c}\text { Hazard ratio } \\
\text { for MVR }\end{array}$ & $\mathbf{9 5} \% \mathrm{CI}$ & $P$ value & $\begin{array}{c}\text { Hazard ratio for } \\
\text { MVR-surgeon volume } \\
\text { interaction }\end{array}$ & $P$ value & $\begin{array}{l}\text { Hazard ratio for } \\
\text { surgeon volume }\end{array}$ & $P$ value \\
\hline Mortality* & 2.86 & $1.09-7.45$ & .03 & 1.05 & .15 & 0.99 & .58 \\
\hline CHF readmission & 2.27 & $0.67-7.70$ & .19 & 0.99 & .92 & 1.00 & .93 \\
\hline Stroke & 1.70 & $0.64-4.50$ & .29 & 0.97 & .11 & 1.03 & .002 \\
\hline Reoperation outcomes $\dagger$ & 0.82 & $0.23-2.92$ & .76 & 1.02 & .58 & 1.03 & .15 \\
\hline
\end{tabular}

$M V R$, Mitral valve replacement; $M V$-repair, mitral valve repair; $C I$, confidence interval. *Reported adjusted hazard ratios are (1) for mortality from a cause-specific hazard model; and (2) for nonfatal outcomes from cumulative sub-distribution hazard models using propensity-matched cohorts. $\dagger$ Of 450 MV-repair cases, 6 underwent subsequent mitral valve surgery during the 4-year follow up period. Of these, only 1 was MV-repair and the remaining were MVRs. Of 450 MVR cases, 3 underwent subsequent MVR and none MV-repair surgery during the 4-year follow-up period. 


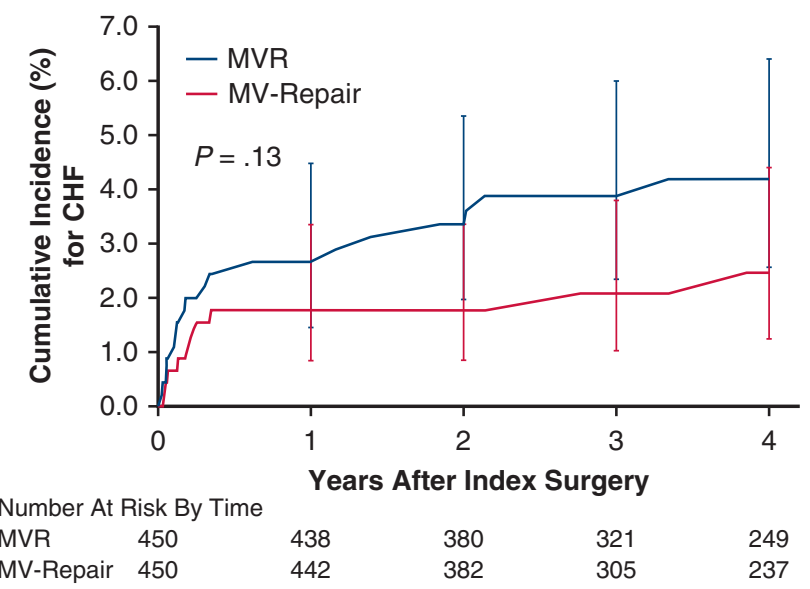

A

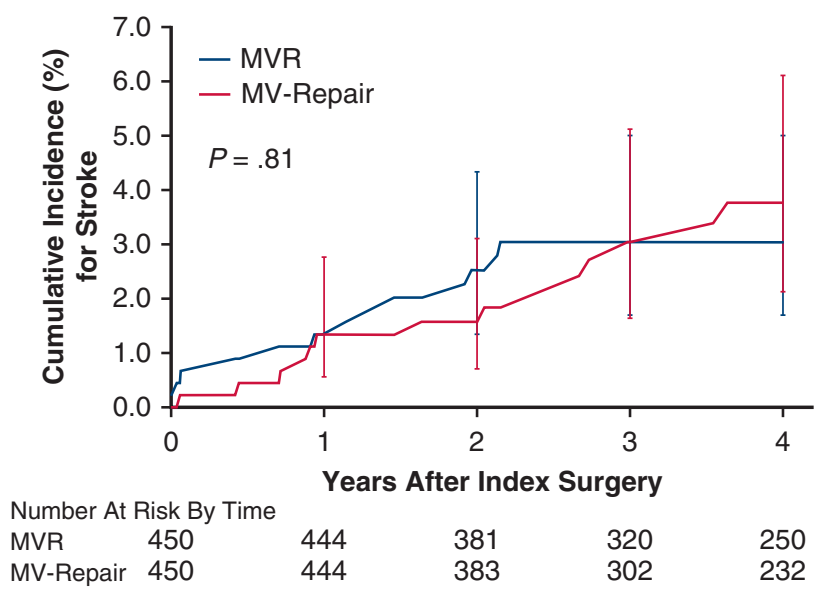

B

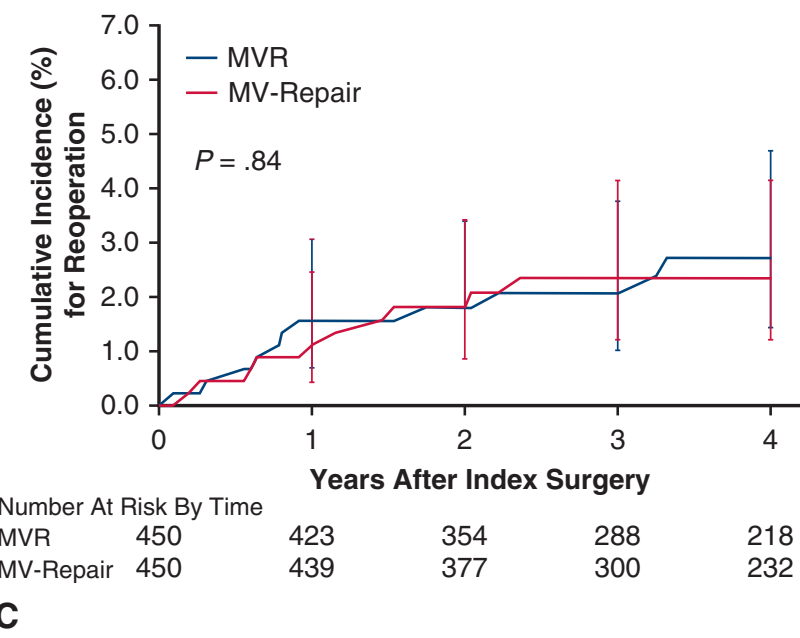

FIGURE 2. A, Cumulative incidence of congestive heart failure readmissions for propensity-matched patients. B, Cumulative incidence of stroke readmissions for propensity-matched patients. C, Cumulative incidence of mitral valve reoperations for propensity-matched patients. $M V R$, Mitral valve replacement; $M V$-repair, mitral valve repair; $C H F$, congestive heart failure.

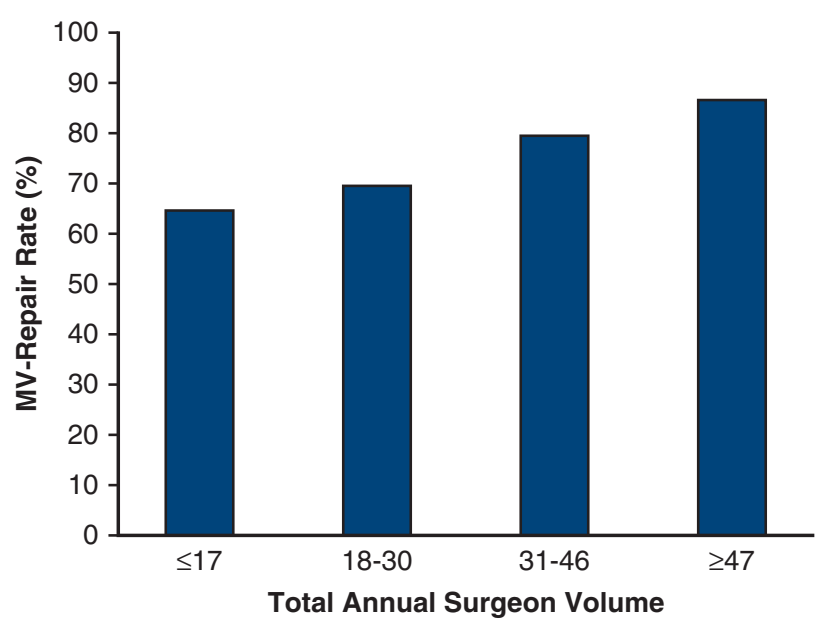

FIGURE 3. Percentage of all mitral valve procedures that are repairs by surgeon volume quartile. $M V$-repair, Mitral valve repair.

recent ACC/AHA guidelines, "Mitral valve repair is reasonable in asymptomatic patients with chronic severe primary $\mathrm{MR}$ (stage $\mathrm{C} 1$ ) with preserved $\mathrm{LV}$ function (LVEF $>60 \%$ and LVESD $<40 \mathrm{~mm}$ ) in whom the likelihood of a successful and durable repair without residual MR is greater than $95 \%$ with an expected mortality rate of less than $1 \%$ when performed at a Heart Valve Center of Excellence." 15 The intent of these guidelines was to identify circumstances in which surgery, specifically repair, is a viable option to watchful waiting for patients with no or minimal symptoms.

We found that $21 \%$ of all patients meeting our inclusion criteria (chronic severe primary MR with preserved LVF and no CHF symptoms) underwent replacement. Also, propensity-matched patients who underwent MV-repair experienced significantly lower mortality rates than MVR patients over the course of 4 years, and no different reoperation rates or readmission rates for stroke and CHF.

These findings are important because the patients in our study are very similar if not identical to the patients identified in the guidelines as being reasonable for MV-repair with the alternative being watchful waiting. Our results show that a surprisingly high percentage of these patients underwent replacement. Those patients experienced significantly greater mortality than MV-repair patients at 4 years and had an in-hospital/30-day mortality that was twice as high $(2.0 \%)$ as the $1 \%$ rate recommended for MV-repair patients in the guidelines. The MV-repair group experienced a $0.7 \%$ in-hospital/30-day mortality.

We also found that surgeons' choice of procedure was strongly related to the volume of mitral valve procedures performed. The percent of mitral valve procedures that were repairs rose consistently from $69 \%$ for the lowest volume quartile to $92 \%$ for the highest volume quartile, and this increase was statistically significant. This finding is 
consistent with the findings in the study of a broader group of patients with MR by LaPar and colleagues ${ }^{27}$ using data from the Society of Thoracic Surgeons. There was not a significant difference in risk-adjusted mortality among the surgeon volume quartiles (AHR for the 21 surgeons in the highest volume quartile vs the other quartiles, $0.63[0.36$, 1.09]). This finding differs from the findings of Gammie and colleagues ${ }^{28}$ who used Society of Thoracic Surgeons data with a broader group of patients with MR.

\section{Limitations}

The relative adverse outcomes, including the use of valve replacement versus repair, could be biased if MVR patients have greater prevalences of risk factors related to adverse outcomes. We tried to minimize this problem when comparing MV-repair and MVR rates by propensity matching patients, which consisted of developing a statistical model that identifies patient characteristics that are associated with the choice of procedure and weights these characteristics accordingly.

Despite these efforts, it is possible that there may be a bias related to variables not contained in the registry that may be predictive of outcomes or choice of procedure. For example, for lack of any alternative, we identified "asymptomatic" from the guidelines as the absence of CHF (defined in the registry as clinical diagnosis of CHF and symptoms requiring treatment for $\mathrm{CHF}$ ). However, it is possible patients in our study had dyspnea unrelated to CHF. If there were more MVR than MV-repair patients with non-CHF symptoms in the propensity match, and these patients were at greater risk of mortality than patients with no symptoms, that would have biased the study against MVR. Also, "preserved left ventricular function" is defined in the guidelines as normal ejection fraction and left ventricular end-systolic diameter $<40 \mathrm{~mm}$, and left ventricular end-systolic diameter was not contained in our registry data. Consequently, some patients in our study may not have had preserved ventricular function, and this could have introduced a bias in relative outcomes of MV-repair and MVR.

We were unable to capture reoperations that occurred out-of-state. We tried to minimize them by excluding outof-state patients undergoing surgery in New York, but some New York state residents could have undergone reoperations out-of-state. It would have been helpful to compare rates of MR following the 2 types of procedures, but we did not have access to that information. Greater repair rates for greater-volume surgeons may have occurred in part because they were referred patients whose valves were more repairable. Conversions were not reported accurately in the database, so part of the greater MVR rates reported may be due to MV-repair patients undergoing conversion. Finally, the low incidence of our study endpoints in these relatively low risk patients means that our study was likely underpowered to detect potentially significant mortality differences in age subgroup analyses and in surgeon volume quartiles. In particular, our finding that surgeon volume was unrelated to mitral valve procedural mortality may be related to limited statistical power caused in part by low event rates in lower-risk patients.

\section{CONCLUSIONS}

In summary, in a large statewide mandated statewide clinical registry, patients with chronic severe primary MR without CHF symptoms and with preserved LVF who undergo MV-repair experienced lower longer-term mortality and no different rates of CHF readmission, stroke readmission, or reoperation than patients who underwent MVR, after adjusting for differences in presentation. There is considerable practice pattern variation among surgeons in the choice of procedure to use, with greater-volume surgeons being more likely than their lower volume counterparts to choose MV-repair. There is not a significant relationship between surgeon mitral volume and mortality, but this may be in part due to low statistical power.

\section{Conflict of Interest Statement}

Dr Chikwe received speaker honoraria from Edwards Lifesciences. All other authors have nothing to disclose with regard to commercial support.

\section{References}

1. Chikwe J, Toyoda N, Anyanwu AC, Itagaki S, Egorova NN, Boateng P, et al. Relation of mitral valve surgery volume to repair rate, durability, and survival. J Am Coll Cardiol. April 24, 2017 [Epub ahead of print].

2. Shuhaiber J, Anderson RJ. Meta-analysis of clinical outcomes following surgical mitral valve repair or replacement. Eur J Cardiothorac Surg. 2007;31:267-75.

3. Mick SL, Keshavamurthy S, Gillinov AM. Mitral valve repair versus replacement. Ann Cardiothorac Surg. 2015;4:230-7.

4. Silaschi M, Chaubey S, Aldalati O, Khan H, Uzzaman MM, Singh M, et al. Is mitral repair superior to mitral valve replacement in elderly patients? Comparison of short- and long-term outcomes in a propensity-matched cohort. JAm Heart Assoc. 2016;5:e003605.

5. Vassileva CM, Mishkel G, McNeely C, Boley T, Markwell S, Scaife S, et al. Long-term survival of patients undergoing mitral valve repair and replacement: a longitudinal analysis of Medicare fee-for-service beneficiaries. Circulation. 2013;127:1870-6.

6. Gaur P, Kaneko T, McGurk S, Rawn JD, Maloney A, Cohn LH. Mitral valve repair versus replacement in the elderly: short-term and long-term outcomes. $J$ Thorac Cardiovasc Surg. 2014;148:1400-6.

7. Chikwe J, Goldstone AB, Passage J, Anyanwu AC, Seeburger J, Castillo JG, et al. A propensity score-adjusted retrospective comparison of early and mid-term results of mitral valve repair versus replacement in octogenarians. Eur Heart J. 2011;32:618-26.

8. Badhwar V, Peterson ED, Jacobs JP, He X, Brennan JM, O'Brien SM, et al. Longitudinal outcome of isolated mitral valve repair in older patients: results from 14,604 procedures performed from 1991 to 2007. Ann Thorac Surg. 2012;94:1870-9.

9. Acker MA, Parides MK, Perrault LP, Moskowitz AJ, Gelijns AC, Voisine P, et al. Mitral-valve repair versus replacement for severe ischemic mitral regurgitation. N Engl J Med. 2014;370:23-32.

10. Dayan V, Soca G, Cura L, Mestres CA. Similar survival after mitral valve replacement or repair for ischemic mitral regurgitation: a meta-analysis. Ann Thorac Surg. 2014;97:758-65.

11. Virk SA, Sriravindrarjah A, Dunn D, Liou K, Wolfenden H, Tan G, et al. A metaanalysis of mitral valve repair versus replacement for ischemic mitral regurgitation. Ann Cardiothorac Surg. 2015;4:400-10. 
12. McNeely CA, Vassileva CM. Long-term outcomes of mitral valve repair versus replacement for degenerative disease: a systematic review. Curr Cardiol Rev. 2015;11:157-62.

13. Gillinov AM, Blackstone EH, Nowicki ER, Slisatkorn W, Al-Dossari G, Johnston DR, et al. Valve repair versus valve replacement for degenerative valve disease. J Thorac Cardiovasc Surg. 2008;135:885-93.

14. Kim JB, Kim HJ, Moon DH, Jung SH, Choo SJ, Chung CH, et al. Long-term outcomes after surgery for rheumatic mitral valve disease: valve repair versus mechanical valve replacement. Eur J Cardiothorac Surg. 2010;37:1039-46.

15. Nishimura RA, Otto CM, Bonow RO, Carabello BA, Erwin JP III, Guyton RA, et al. 2014 AHA/ACC Guideline for the Management of Patients with Valvular Heart Disease: a report of the American College of Cardiology/American Heart Association Task force on Practice Guidelines. Circulation. 2014;129:2440-92.

16. Rosenbaum PR, Rubin DB. The central role of the propensity score in observational studies for causal effects. Biometrika. 1983;70:41-55.

17. Rosenbaum PR. Optimal matching for observational studies. J Am Stat Assoc. 1989;84:41-55.

18. Ming K, Rosenbaum PR. A note on optimal matching with variable controls using the assignment algorithm. J Comput Graph Stat. 2001;10: 455-63.

19. Gu XS, Rosenbaum PR. Comparison of multivariate matching methods, structures, differences, and algorithms. J Comput Graph Stat. 1993;2:405-20.

20. Fine JP, Gray RJ. A proportional hazards model for the subdistribution of a competing risk. J Am Stat Assoc. 1999;94:496-509.
21. Austin PC, Lee DS, Fine JP. Introduction to the analysis of survival data in the presence of competing risks. Circulation. 2016;133:601-9.

22. Gray R. A class of $\mathrm{K}$-sample tests for comparing the cumulative incidence of a competing risk. Ann Stat. 1988;16:1141-54.

23. Klein JP, Moeschberger ML. Survival Analysis: Techniques for Censored and Truncated Data. New York: Springer-Verlag; 2005.

24. Zeger SL, Liang KY, Albert PS. Models for longitudinal data: a generalized estimating equation approach. Biometrics. 1988;42:1049-60.

25. Ellison P. Survival Analysis Using the SAS System. Cary, NC: The SAS Institute 1995.

26. Ghali WA, Quan H, Brant R. Comparison of two methods for calculating adjusted survival curves from proportional hazards models. JAMA. 2001 286:1494-7.

27. LaPar DJ, Ailawadi G, Isbell JM. Mitral valve repair rates correlate with surgeon and institutional experience. J Thorac Cardiovasc Surg. 2014;148: 995-1003.

28. Gammie JS, O'Brien SM, Griffith BP, Ferguson TB, Peterson ED. Influence of hospitals procedural volume on care process and mortality for patients undergoing elective surgery for mitral regurgitation. Circulation. 2007;115: $881-7$.

Key Words: mitral valve repair, mitral valve replacement, mitral valve mortality, propensity matching, mitral valve readmissions, mitral valve reoperations

Readers who found these articles interesting may also like to read the following papers found in recent and future issues of our sister publications, Seminars in Thoracic and Cardiovascular Surgery and Operative Techniques in Thoracic and Cardiovascular Surgery!

\section{Adult: Mitral Valve}

ORIGINAL SUBMISSION: Is Surgical or Catheter-based Interventions an Option After an Unsuccessful Mitral Clip? Felix Kreidel. Semin Thoracic Surg 2018: 152-157.

Editorial Commentary: With Every New Technology Comes a Learning Curve. Saina Attaran. Semin Thoracic Surg 2018: 158-159.

ORIGINAL SUBMISSION: Tiara Valve Implantation in a Patient With Previously Implanted Mono-disk Mechanical Aortic Prosthesis. Enrico Ferrari. Semin Thoracic Surg 2018: 160-163.

Editorial Commentary: Connubial Bliss or Distress? Transcatheter Mitral Valve Implantation With Mechanical Aortic Prostheses. Mohamad Alkhouli. Semin Thoracic Surg 2018: 164-165.

CASE REPORT: Minimally Invasive SAPIEN in Mitral Annular Calcification Following Transcatheter Aortic Valve Replacement: Feasibility and Lessons Learned. Tom C. Nguyen. Semin Thoracic Surg 2018: In press. 


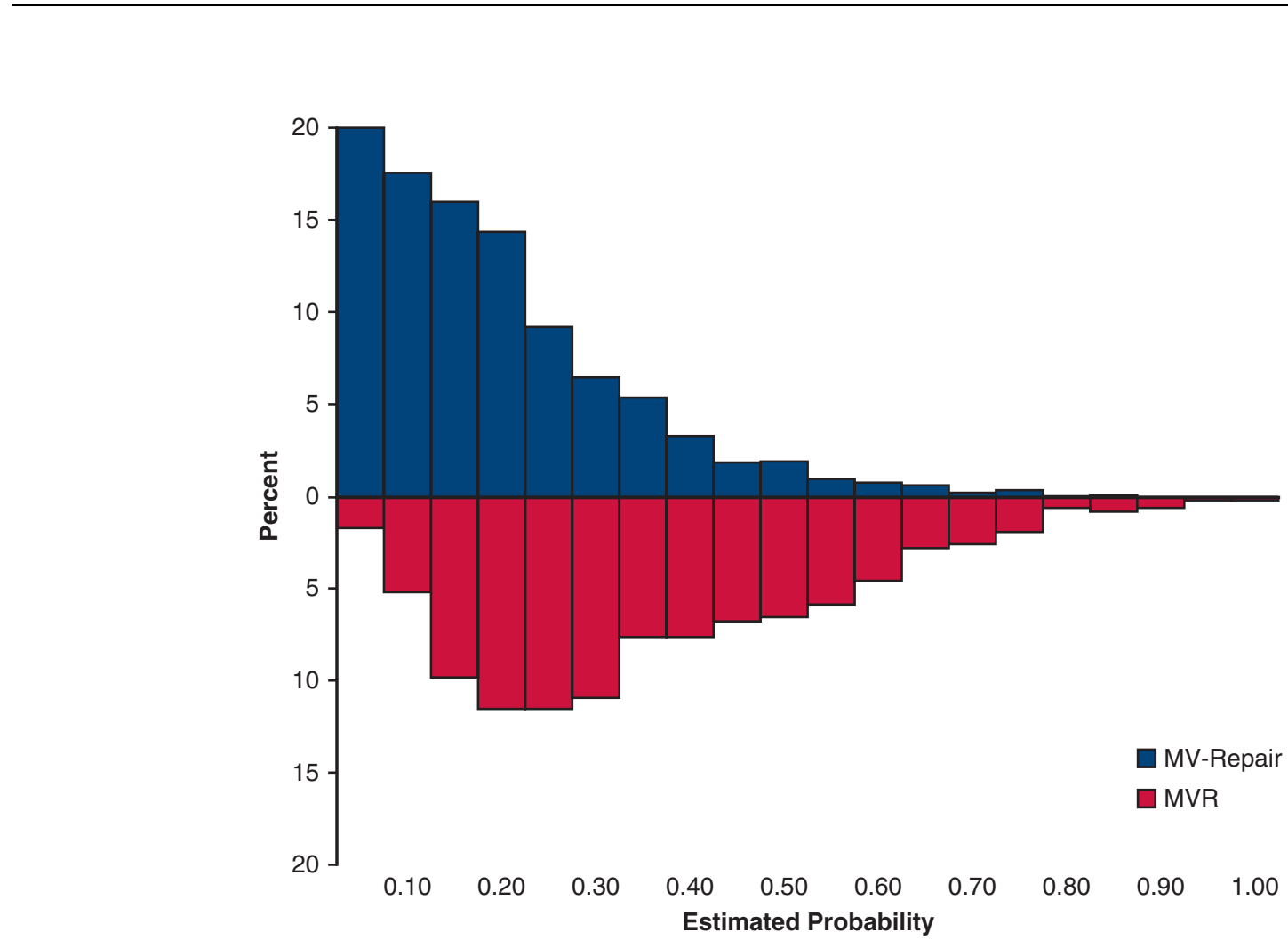

FIGURE E1. Frequency distributions for probability of repair and replacement before propensity matching. MV-repair, Mitral valve repair; $M V R$, mitral valve replacement.

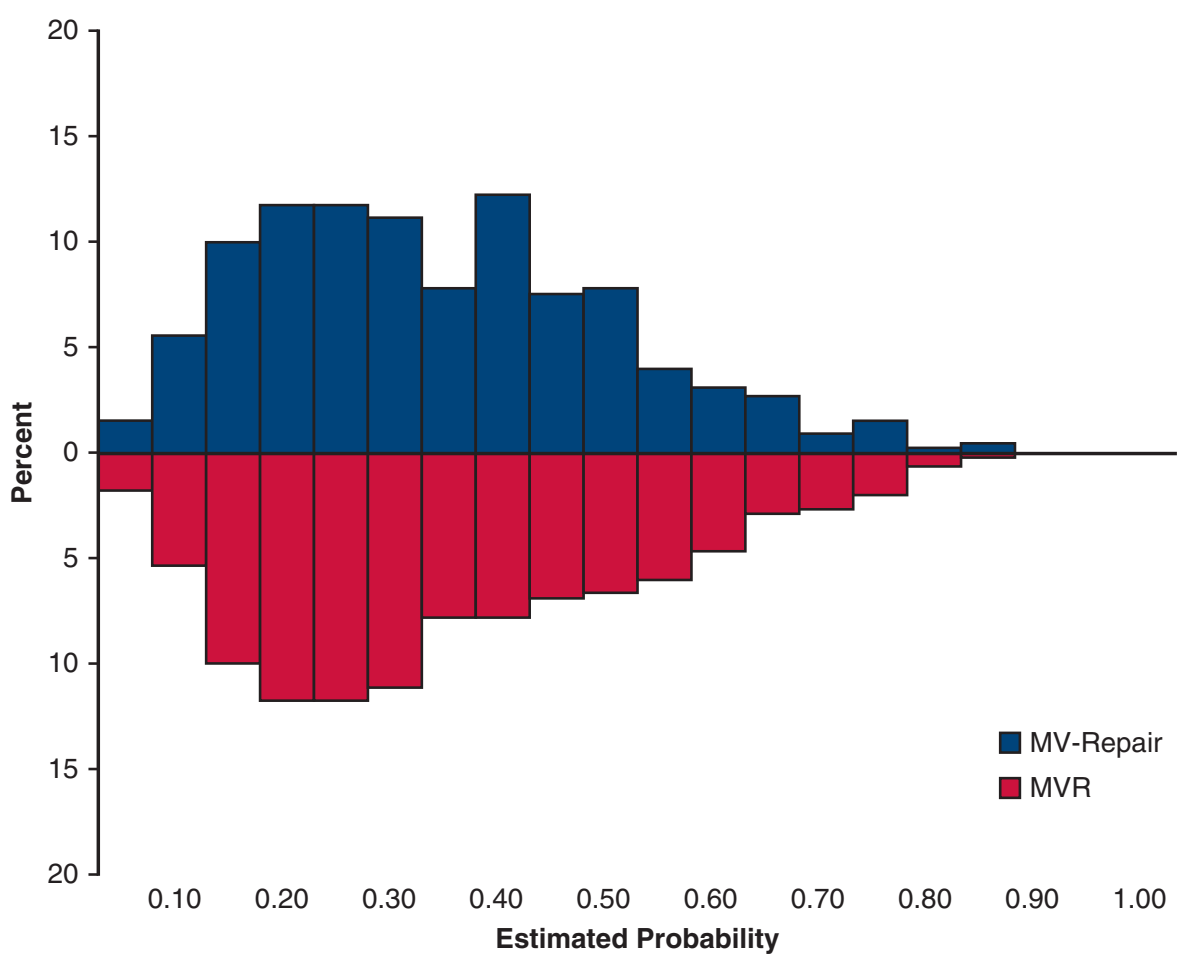

FIGURE E2. Frequency distributions for probability of repair and replacement after propensity matching. $M V$-repair, Mitral valve repair; $M V R$, mitral valve replacement. 
TABLE E1. Multivariable risk equation for predicting mitral valve replacement in patients undergoing isolated mitral valve surgery: New York State, 2008 to 2014

\begin{tabular}{|c|c|c|c|c|}
\hline Risk factor & Prevalence & Coefficient & $P$ value & Odds ratio $(95 \% \mathrm{CI})$ \\
\hline Surgeon MV-repair volume & - & -0.0482 & $<.001$ & $0.95(0.94-0.96)$ \\
\hline Age, $y$ & - & 0.0144 & .004 & $1.01(1.00-1.02)$ \\
\hline Body surface area, $\mathrm{m}^{2}$ & - & -0.1534 & .56 & $0.86(0.51-1.44)$ \\
\hline Stenosis, aortic or/and tricuspid valves & 1.90 & 0.8688 & .02 & $2.38(1.16-4.88)$ \\
\hline Aortic valve incompetence, mild & 12.97 & 0.1169 & .49 & $1.12(0.81-1.56)$ \\
\hline Aortic valve incompetence, moderate/severe & 2.74 & -0.0266 & .94 & $0.97(0.49-1.93)$ \\
\hline Tricuspid valve incompetence, mild & 29.00 & -0.0279 & .83 & $0.97(0.75-1.26)$ \\
\hline Tricuspid valve incompetence, moderate/severe & 12.35 & 0.1630 & .36 & $1.18(0.83-1.66)$ \\
\hline Female sex & 46.57 & 0.7331 & $<.001$ & $2.08(1.60-2.72)$ \\
\hline \multicolumn{5}{|l|}{ Race } \\
\hline White & 87.82 & \multicolumn{3}{|c|}{ Reference } \\
\hline Black & 7.35 & 0.4551 & .02 & $1.58(1.06-2.35)$ \\
\hline Other & 4.83 & 0.3240 & .20 & $1.38(0.84-2.28)$ \\
\hline Peripheral vascular disease & 1.90 & 0.4660 & .19 & $1.59(0.79-3.21)$ \\
\hline Cerebrovascular disease & 4.78 & 0.4121 & .08 & $1.51(0.95-2.39)$ \\
\hline CHF, past & 11.82 & 0.5047 & .001 & $1.66(1.22-2.26)$ \\
\hline COPD & 12.22 & 0.5772 & $<.001$ & $1.78(1.32-2.40)$ \\
\hline Extensive aortic atherosclerosis & 0.66 & 0.3692 & .54 & $1.45(0.44-4.77)$ \\
\hline Diabetes & 5.22 & 0.6910 & .003 & $2.00(1.27-3.13)$ \\
\hline \multicolumn{5}{|l|}{ Renal dysfunction } \\
\hline Serum creatinine $<1.3 \mathrm{mg} / \mathrm{dL}$ & 91.19 & \multicolumn{3}{|c|}{ Reference } \\
\hline Serum creatinine $1.3-2.0 \mathrm{mg} / \mathrm{dL}$ & 7.22 & 0.0372 & .87 & $1.04(0.67-1.61)$ \\
\hline Serum creatinine $\geq 2.1 \mathrm{mg} / \mathrm{dL}$ or/and Renal dialysis & 1.59 & 1.1931 & .003 & $3.30(1.50-7.26)$ \\
\hline Intercept & -1.8220 & & & \\
\hline C-statistic & \multicolumn{4}{|c|}{0.773} \\
\hline
\end{tabular}

$C I$, Confidence interval; $M V$-repair, mitral valve repair; $C H F$, congestive heart failure; $C O P D$, chronic obstructive pulmonary disease. 